\title{
Going global: professionals and the micro-foundations of institutional change
}

\author{
Brooke Harrington*
}

\author{
Department of Business and Politics, Copenhagen Business School, Porcelaenshaven 24, 2000 Frederiksberg, Denmark \\ *Corresponding author. Email: bh.dbp@cbs.dk.
}

\begin{abstract}
This study links theories of relationality and institutional change to deepen understanding of professionals' role in globalization. In previous institutional research, it has been conventional to treat professionals as agents of firms or transnational organizations, and institutional change as the result of planned, strategic 'professional projects'. By bringing a relational analysis to bear on the problem of institutional change, this study reasserts the theoretical significance of individual agency and everyday interactions between professionals and their clients, peers, and organizational environment. It also broadens the model of agency to include invention and improvisation by individual professionals, as a counterpart to collective strategic action. The argument is based on data from a 16-nation study exploring the emergence of a particular 'globalized localism': the transformation of the asset-holding trust from a tool of medieval English landowners into a mainstay of contemporary international finance. Drawing on interviews with 61 wealth management professionals in Europe, Asia, Africa, and the Americas, this article uses their accounts of the diffusion and deployment of trusts to specify a new, more detailed model of the ways local practices and ideas develop into global institutions.
\end{abstract}

KEYWORDS : professions, globalization, wealth management.

\section{INTRODUCTION}

Through what mechanisms do local professional practices and concepts turn into global institutions? This article seeks to address the theoretical lacuna around this question by examining its micro-level foundations. In particular, it will address questions surrounding the manifestations of agency by professionals working in trans-national environments (Dezalay and Garth 2002; Carruthers and Halliday 2006). The specific forms of work through which professionals effect institutional change in the global context are still poorly understood and undertheorized (Muzio, Brock, and Suddaby 2013). Extant theories have privileged macro-level strategic actionwith organizations as actors and planned, deliberate change as the primary form of agency-largely to the exclusion of individual professionals and their situated improvisations at work (Smets, Morris, and Greenwood 2012). This article addresses the many calls for a course correction in work on institutional change and agency (e.g. Faulconbridge 2007; McCann and Ward 2010; Malsch and Gendron 2013; Adamson, Manson, and Zakaria 2015); it does so by linking institutional and relational theories in an analysis of an elite trans-national professional group.

This study will propose a multi-level account of the interplay between trans-national institutions and the micro-level practices of individual professionals (Smets and Jarzabkowski 2013). It will offer a 
relational conception of the origins of institutional change by focusing analytically on the encounters professionals have with clients, peers and policymakers. Although relational analyses have generated a thriving literature in sociology and economic geography, this will be the first attempt to integrate them with mainstream institutional theories of professional practice. In institutional research, it has been conventional to examine agency as planned and collective, originating primarily from the organizational level. This perspective has neglected the domain of everyday institutional work by individual professionals (Adamson, Manson, and Zakaria 2015). The result has been a persistent gap in the literature: 'institutionalists have tended to neglect the ... linkages between micro-processes and institutions' (Malsch and Gendron 2013: 872). Bringing a relational analysis to bear on the study of institutional change could address this shortcoming.

As Muzio, Brock, and Suddaby (2013) have pointed out, there is a particularly urgent need to understand how professions and professionals shape the development of contemporary business practices in the trans-national arena. Of special interest is the phenomenon of 'globalized localisms' (Jenson and de Sousa Santos 2000; Carruthers and Halliday 2006), which consist of practices and ideas exported from core countries to the rest of the world. Examples include the spread of American-style corporate law practice (the 'Wall Street firm' described by Dezalay 1990), and the case that will form the empirical focal point of this article: the diffusion of the English common law trust to become a standard tool of international finance. As the data presented below will show, this case exemplifies the observation that that 'global arenas and global processes are constructed from below' (Fourcade and Savelsberg 2006: 514).

What is new in this study is the evidence that 'below' begins at the level of encounters between individual professionals and their clients, peers, and other actors in the legal-organizational environment. Through this relational analysis, the article offers a more nuanced examination of agency and a deeper understanding of the dynamics of institutional change. Explaining change has been a long-standing challenge facing the study of institutions; since the seminal work of Brint and Karabel 1989, a growing stream of research has pointed to the central role of professions as 'a clear causal agent of institutional change' (Suddaby and Viale 2011: 424). However, the scholarly conversation has been centered for some time on explanations involving structures, rulemakers and 'critical projects' (Fiss and Hirsch 2005). Research streams like those in the 'world polity' tradition (Meyer et al. 1997), or theories that privilege structural relationships among states and classes (Skocpol 1979; Poulantzas 2000), overlook the negotiated encounters and situated improvisations that make up the bulk of professional activity in trans-national settings. As a result, they offer little insight into how professionals form lines of action at the local level.

This article offers to move the dialogue in a new direction by integrating the relational perspective with the institutional. This contributes to the literature on institutional analysis by specifying more clearly how professionals exercise agency, and by specifying a multi-level model of 'globalized localisms'-showing how individuals' situated improvisations can diffuse from the local level to the trans-national one. In particular, this article develops two theoretical insights from the case of wealth managers and their use of trusts. First, the data illustrate the significance of inventive, contingent problem-solving as a key application of professional expertise. Extending recent research by Smets and Jarzabkowski (2013), as well as older insights from Boreham (1983), this article links institutional change to the neglected realm of situated improvisations in professional work. Second, the data show how the context of trans-national professional service (Dezalay and Garth 1995; Carruthers and Halliday 2006) makes such improvisations increasingly unavoidable, as the intersection of unrelated jurisdictional rules and norms necessitates invention (Thornton, Ocasio, and Lounsbury 2012). The intended contribution is a more nuanced, situated account of the manifestations of professional agency, and the impact of that agency on change in global institutions.

\section{LITERATURE REVIEW}

In research on professions and institutional change, agency is a vexed issue. As the source of change, agency is acknowledged as a central issue for scholars. 
However, key questions-including whose agency matters, and how it is expressed-remain undertheorized. To remedy this problem, this study proposes to link institutional analysis with relational theory. This means focusing on expressions of agency in practice, within the micro-level encounters (with clients, peers, policy-makers and others) that make up the bulk of everyday work in many professions (McCann and Ward 2010).

By taking a relational approach to explaining institutional change, this study responds to calls for more research on the local origins of global institutions. As Fourcade and Savelsberg (2006: 516) observe, 'the global does not exist outside of its relationship to, or more specifically its incarnation in, local practices'. Yet these interpersonal encounters are usually overlooked in studies of trans-national institutional change (Carruthers and Halliday 2006). Since professionals literally incarnate or embody institutions in encounters with others, a relational analysis of institutional change at the global level would seem warranted.

\section{Professionals and institutional change}

A well-established stream of research has examined the seeming paradox of change within institutions, which are defined in part by their stability over time (Suddaby and Viale 2011). Recent analyses have accorded a central role to professions, treating them as 'both the mechanisms for and the primary targets of institutional change and transformation' (Malsch and Gendron 2013: 871). However, this literature suffers from several conceptual gaps that exclude key aspects of professional practice.

This article will focus on three of those gaps. First, most research on institutions and professions focus on professions transforming themselves, overlooking 'their wider role in building and transforming political, social, and economic institutions' (Muzio, Brock, and Suddaby 2013: 704). Second, studies that acknowledge professions' role in wider forms of institutional change treat professionals not as individuals, but as representatives of firms (Dezalay and Garth 2002), or actors 'under the sponsorship of transnational institutions' (Muzio, Brock, and Suddaby 2013: 707; see also Fourcade 2006). In other words, the focal actors in institutional change are organizations, leaving the domain of individual professional activity unexplored (Powell and Colyvas 2008).

Third and most importantly, there is gap in the current literature regarding agency-how professionals enact institutional change. To be sure, recent work has specified forms of agency that might provoke change, such as 'advocacy, definition, vesting, and constructing normative associations and identities' (Lefsrud and Suddaby 2012: 319; see also Daudigeos 2013). However, there has been inadequate attention to the nuances of form that agency can take (Smets and Jarzabkowski 2013), leaving many important questions unanswered.

For example, must all institutional change in which professionals are involved be a deliberate effort, 'a conscious and systematic political project' (Muzio, Brock, and Suddaby 2013: 702)? Much of the literature assumes this to be so (Larson 1977; Suddaby and Viale 2011; Daudigeos 2013). This approach understands professionals' institutional work as purposive action based on planned, established procedures, and often carried out by organizations such as professional societies (Jepperson 1991; Lawrence and Suddaby 2006).

Although this is an accurate characterization of many professional activities, it leaves out an important dimension of work that is particularly characteristic of expert authority: invention and indetermination (Boreham 1983). Professional work resists standardization (Abbott 1991; Freidson 2001). An adequate analysis of the professions must therefore account for improvisations and non-routine responses to problem-solving, which can lead to unforeseen and unintended consequences. Such responses can be provoked when professionals 'come in contact with innovations' (Daudigeos 2013: 734), or institutional conflicts (Perkmann and Spicer 2007) -both of which are common events in trans-national practice (Delmestri 2006). For professionals working at the intersection of diverse legal, economic, and cultural systems, action is neither random nor the result of grand strategy; rather, it is driven by incremental problem solving 'motivated by the experience of novel institutional complexity' (Smets, Morris, and Greenwood 2012: 899).

This study seeks to expand the scholarly conversation to encompass both sources of institutional change: those stemming from situated improvisation, 
along with the planned, strategic 'professional projects' model that is conventional in current research. Such an analysis is already possible, but largely unrealized, within the institutional literature. A relational model helps us realize these insights analytically.

\section{Relationality and professional work}

A relational perspective is agency-focused, treating the social world as comprised of 'dynamic, unfolding relations', as opposed to a world of rules, structures and 'fixed entities with variable attributes' (Emirbayer 1997: 281, 286). Relationality is thus distinct from interactional analysis, which understands social actors as fixed analytical givens (Abbott 1988). Most importantly, with regard to institutional change, relational analyses allow for emergence, change, and improvisations (Emirbayer 1997: 292). Thus, a relational view of agency allows us to analyse key aspects of professional work that are neglected in institutional theory: the strategic, inventive uses of indeterminacy and expert knowledge (Boreham 1983).

Relational theory originates in what Emirbayer (1997: 296) has called a 'sociology of occasions', in which agency arises to meet the demands of situated encounters. In meetings, consultations and conferences (Daudigeos 2013), many of which occur faceto-face (Faulconbridge 2007), professionals must respond to contingencies on the spot. Not only must they develop lines of action 'with lightning speed' (McCann and Ward 2010: 175), but for those working in trans-national settings, the intersection of independent systems of law, culture, and institutions means that established plans and routines may be of very little use (Smets and Jarzabkowski 2013). A different kind of agency is required-one that relational theory is well-equipped to analyse.

Relational theory differs from the better-known network analysis of professional work in that network theory focuses primarily on the structure of ties. In contrast, relational approaches to the professions-such as policy professionals (McCann and Ward 2010) and lawyers (Faulconbridge 2007) look primarily at the content of interpersonal transactions. In this way, relational theory offers more insight into the sources of change. As Faulconbridge (2008: 186) puts it,
' $\ldots$ the relational network forms that underlie economic activities are described not as static architectures, but as ongoing socioeconomic accomplishments that are constructed through the negotiation of, among other things, complex and dynamic institutional backdrops.'

That is, if network theory takes a 'mechanistic' approach to interpersonal ties, relational theory is distinct by virtue of its attention to 'the social processes that constitute these relationships' (Dicken et al. 2001: 105).

If, as some have observed, institutionalism needs a better analysis of how agency occurs in professional settings (McCann and Ward 2010), relational theory offers a means to achieve those aims. This is a particularly noteworthy problem given the significance of globalization to institutional change dynamics. The literature on globalization has pointed up the role of professionals in creating 'successfully globalized local institutional solutions' (Santos 2002: 214), including 'globalized localisms' like the Wall Street legal firm (Dezalay 1990) and Anglo-Saxon financial models (Frankel 1998). However, we must turn to relational theory for an account of agency-specifically, the micro-level processes that 'allow the dis- and re-embedding of practices' (Faulconbridge 2007: 926) from one set of national and institutional contexts to another.

\section{Linking the perspectives}

In summary, the theoretical model proposed here extends understanding of institutional work by bringing in situated improvisations as a source of institutional change in the trans-national realm of professional activity. This approach addresses a neglected dimension of agency in institutional theory, which has too often privileged intentionality and foresight to the exclusion of alternative models of practice (Lawrence and Suddaby 2006). Yet contemporary professional service contexts require 'practical-evaluative improvisations' in which 'actors develop and realize their interests' not through planning but through practice (Smets and Jarzabkowski 2013: 1282-1283). This is particularly true in the international realm, in which professionals are continually confronted with novel institutional configurations in the form of laws, professional rules, 
cultures, and norms meeting across jurisdictions (Delmestri 2006; Thornton, Ocasio, and Lounsbury 2012). In such cases, narrow construction of institutional agency as based on 'standardized interaction sequences' or 'established procedures' (Jepperson 1991: 143) excludes important realms of professional practice.

Relational theory is particularly helpful in bringing analytical attention to the neglected improvisational dimension of agency, since it accounts for the ways that particular relational settings call forth action on the spot, without a predetermined plan. As Emirbayer (1997) explains, the social order is continually being reconstructed through practice. Faced with the complexity created by 'intersecting institutional streams' (Delmestri 2006: 1515), the constitution of professional relations inevitably demands the invention of new, non-routine lines of action.

Thus, the linkage between the relational and institutional perspectives proposed here allows us to theorize agency in a new way, accounting for both improvisational and intentional forms of institutional change in the domain of trans-national professional service. Institutional theory as it is currently formulated gives insufficient acknowledgement to the multi-dimensional nature of agency, emphasizing planning at the expense of practice. Bringing in relationality enables us to theorize the interplay of different forms of agency' (Smets and Jarzabkowski 2013: 1282), which is both of a source of institutional change and a response to institutional complexity in global professional activity.

\section{RESEARCH CONTEXT}

As a case study of professional relationality and institutional change, this article looks at the diffusion of a legal structure known as the asset-holding trust. Trusts are a device for protecting the assets of individuals and firms - which might include, cash, land, stocks and bonds, or works of art-from taxes, creditors, and regulators. This protection is achieved through a legal fiction with financial consequences: the separation of ownership into two parts, one legal and one beneficial. When trusts are created, the obligations of ownership (such as the payment of taxes on an asset) go to one set of actors, while the benefits (use and enjoyment of the asset) go to another set of actors. The actors with the obligations are called fiduciaries, while the actors who enjoy the benefits are called beneficiaries (Hofri 2014).

Trusts developed during the time of the Crusades as 'a passive device for holding ancestral land' (Langbein 1995: 636), designed to protect the wealth of English nobles from feudal taxation and inheritance rules. However, when conditions changed and feudal laws were supplanted, the trust did not fade into obscurity. Instead, it was repurposed and applied to solve new problems:

'Although feudal law no longer needs evading, the trust has endured because it has changed function. The trust has ceased to be a conveyancing device for holding freehold land and has become instead a management device for holding financial assets' (Langbein 1995: 637).

From its origins as a solution to problems faced by 14th century English landowners, the trust is now a mainstay of corporate and private wealth management around the world, exemplifying the concept of a 'globalized localism' (Santos 2002).

Formally, the law defines trusts as 'a fiduciary relationship with respect to property' (Langbein 1995: 627). In other words, trusts are neither contracts nor corporations, but a legal relationship among individuals. This makes them well-suited to a relational analysis, particularly because in contemporary practice, the fiduciary role is usually occupied by professionals. These professionals, known as wealth managers, maintain, and protect the trust assets on behalf of the beneficial owners; trusts cannot exist without the intervention and continuous participation of such agents. Furthermore, since many trusts now contain assets spread across numerous jurisdictions and nation-states, wealth management typically involves coordination of an international team that includes specialists in the accounting rules and tax laws of each country where a client or firm owns assets (Parkinson 2005). ${ }^{1}$ This requires frequent interaction between the wealth manager charged with ownership responsibility for the trust and a suite of professional peers, as well as firms and governance institutions. Thus, trusts offer a particularly fruitful empirical case for research on relationality among professionals. 
Wealth management is an emergent transnational profession characterized by a distinctive application of financial-legal expertise, as well as a specific set of practices, networks, and political activities (Harrington 2012a). Trusts, along with offshore banks and shell corporations, are key tools of their trade (Parkinson 2005). This profession has received little attention from social scientists, both because it is relatively new and because its power lies in maintaining discretion. Since the profession was not established formally until 1991, its boundaries are still fluid, and entry is relatively open, although limited by a credentialing process (Harrington 2012a). Members come from a wide variety of backgrounds: law and accounting are dominant, but it is not uncommon to find former academics and others practicing as wealth managers. Most, but not all, belong to the London-based professional body known as the Society of Trust and Estate Practitioners (STEP), which currently represents 20000 members in 95 countries.

The emergence of the trust as a standard tool or 'technology' (Lefsrud and Suddaby 2012) of global finance owes much to the professional relations of wealth managers, both as individuals and through STEP. Their diffusion of the trust trans-nationally also makes for a compelling example of institutional change. Through the work of wealth managers, the trust has been deployed for purposes never imagined in the Middle Ages, such as investing and securitization (Parkinson 2008). For example, a crucial function of trusts in the modern financial system is to act as a container for corporate shares; this is the organizational structure underlying mutual funds (Langbein 1997). Thus, though it is 'the most distinctive achievement' of the Anglo-American legal tradition (Maitland 2011 [1909]: 23), the trust has become a pillar of global finance. This case thus exemplifies Lefsrud and Suddaby's (2012: 328) observation that institutional change occurs when 'professionals introduce old rule structures and technologies into new contexts'.

\section{METHODOLOGY}

This article is part of a work in progress, based on 61 interviews thus far, conducted in English in 16 countries, spanning Europe, North and South America, Asia, Africa, the Caribbean, and the Middle East.
Interview participants included many of the leading members of the international wealth management community, as well as officers of the professional association, the London-based STEP. Participants were selected through attendance at five STEP training courses, as well as three international conferences in key regions of global practice. Figure 1 shows the distribution of research sites and the number of participants interviewed in each locale.

The semi-structured interviews, which lasted a minimum of $40 \mathrm{~min}$ and a maximum of $3 \mathrm{~h}$, focused on the participants' most common day-to-day tasks, challenges, and conflicts. Participants were also asked to share their observations about trans-national variations and institutional changes taking place within the wealth management industry. Audio and video taping were not permitted in many of the organizational settings where the interviews were conducted, so for the sake of consistency, all the participants' responses were recorded through note-taking on a laptop computer.

Table 1 presents basic demographic data on the interview participants, including gender, age, race/ ethnicity, country of origin, and professional background. The table also indicates how many participants were members of STEP. This is important in order to address concerns about sample bias. Although is the only professional society that represents wealth managers (Harrington 2012a), not all wealth managers are members. This is partly because STEP itself is a relatively new organization, founded in 1991, and partly because wealth management as a field is characterized dynamic boundaries, to a greater extent than is characteristic of more established professions, such as medicine and the law.

As Dezalay and Garth (1995) have observed, we cannot accept uncritically the claims of certain groups-including STEP — to represent a profession. Instead, scholars must examine these claims and activities, and make them objects of study: a challenge the author has addressed in a different work (Harrington 2012 b). In acknowledgement of this contested terrain, and to reduce the possibility that this study would capture only the dynamics of the professional society, as opposed to those of the profession as a whole, the author purposefully included in the study a significant proportion of wealth managers who have never joined STEP; these individuals comprise $31 \%$ of the sample. 


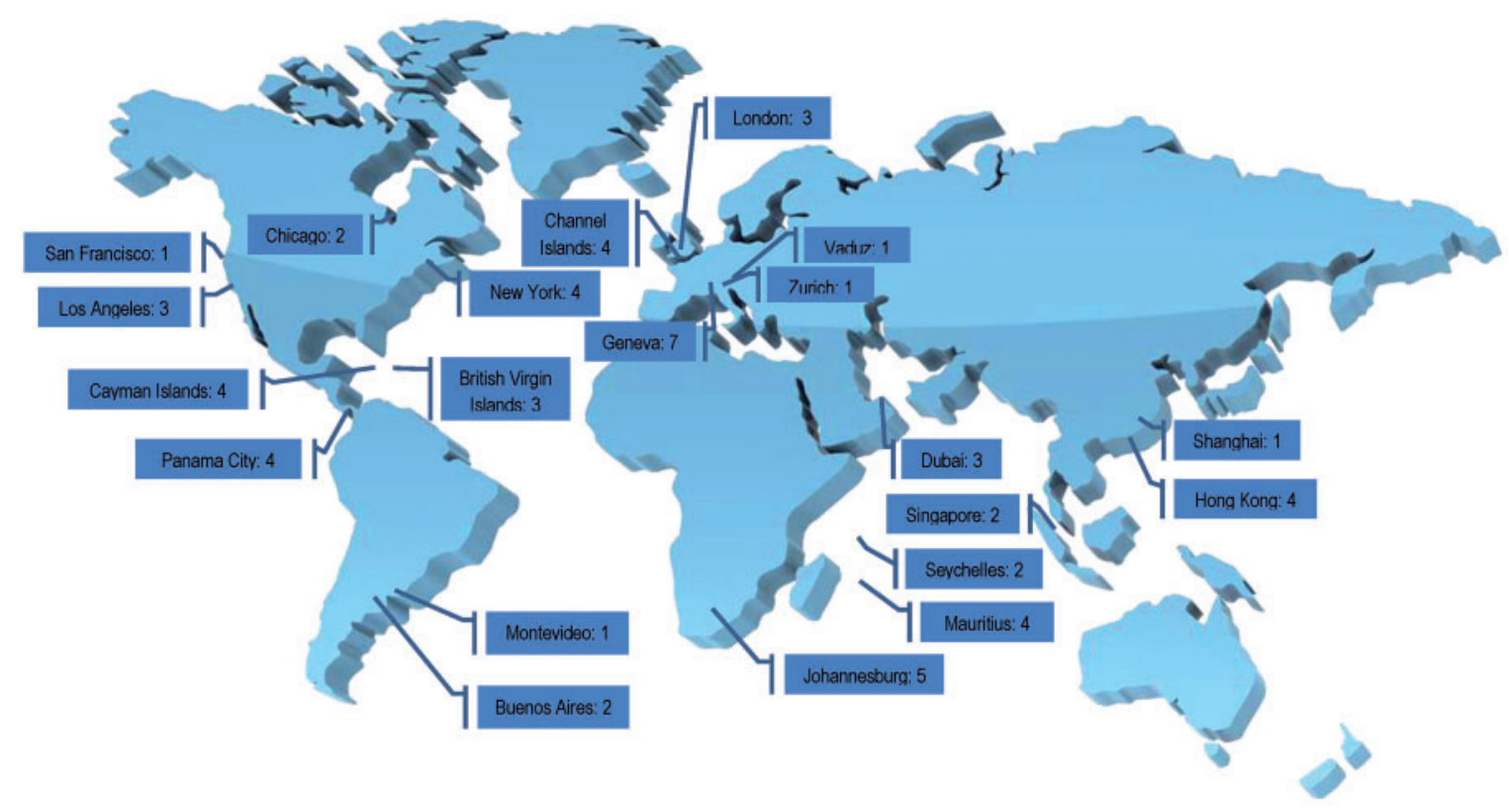

Figure 1. Quantity and location of wealth manager interviews.

Data analysis followed an inductive theory development process (Baker and Nelson 2005). Following the methods described by Eisenhardt (1989), the author searched for major themes in the interview data and compared these themes with concepts from the literatures on professions and globalization. Having identified the central themes of relationality and institutional change, the author used an iterative process-moving back and forth between the data and relevant literature-to develop an emerging theory of the diffusion of local professional activity to the global-institutional level. In particular, the author examined the data for information on the interaction processes that catalyse professional innovation, and the patterns through which the resulting solutions spread internationally. The focus was not on testing, but on building a more detailed model linking the micro level of professional interactions and its connection to the trans-national level of analysis. This led to the development of the conceptual model shown in Figs. 2 and 3.

\section{FINDINGS}

Trusts as relational structures

Through their use of trusts, professional wealth managers have developed work patterns distinct from those of their peers in finance and law. For example, while retaining legal counsel or consulting a financial adviser now commonly leads to relationships lasting from 3 to 6 years (Howcroft, Hewer, and Hamilton 2003; Kim 2009), wealth managers often maintain clients over decades. One study characterized the profession in terms of client 'relationships of long and uncertain duration, usually measured in lives' (Langbein 1995: 661). It is not uncommon to find wealth managers working with the children or grandchildren of their original clients (Hughes 1997).

This is not unique to wealth management, but rather is a feature of high-end professional services, particularly to elites (Pincon and Pincon-Charlot 1998). Much like providers of luxury services, wealth managers are expected to provide their high-networth clients with minutely personalized interactions (Sherman 2011). As Hanlon (2004: 190) writes of the lawyers who served the wealthiest and most powerful members of 19th century Britain, 'In these conditions, trust is created through copresence, familiarity, face-to-face contact and so on ... This puts relationships ... at the apex of selling complex products in professional market'. Thus, a recent global survey of wealth managers found that the top five skills practitioners needed to succeed in the profession were not technical, but relational; these 
Table 1. Demographic composition of interview sample $(N=61)$

\begin{tabular}{lcc}
\hline Characteristic & Count & Percentage (\%) \\
\hline Gender & & \\
Women & 18 & 30 \\
Men & 43 & 70 \\
Age group & & \\
20s & 1 & 2 \\
30s & 21 & 34 \\
40s & 20 & 33 \\
50s & 11 & 18 \\
60s & 8 & 13 \\
Race/ethnicity & \\
White & & \\
Black & 42 & 69 \\
Indian or Pakistani & 6 & 10 \\
East Asian & 5 & 8 \\
Latino/a & 3 & 5 \\
Professional background & 5 & 8 \\
Law & & \\
Private banking & 22 & 36 \\
Corporate finance & 19 & 31 \\
Accountancy & 6 & 10 \\
Other & 6 & 10 \\
STEP membership & 8 & 13 \\
Yes & & 69 \\
No & 42 & 31 \\
\hline
\end{tabular}

included 'active listening' and 'developing rapport' (Cox 2013). As Alan, a British trustee based in Hong Kong, observed,

'Trusts are not a commodity-they are a living, evolving relationship between a trustee and the group of people to whom the trustee has duties. It's not a static thing. It's a relationship.'

Crucially, the kind of trust and rapport necessary to establish these relationships is based on personal encounters-thus the need for a relational analysis. Previous research has suggested that professionals derive the power to instigate institutional change largely from their roles as members of firms or trans-national organizations (e.g. Fourcade 2006; Daudigeos 2013). However, the data from this study suggests that for wealth managers, the ability to diffuse trusts as a form of professional practice depends on their individual relational skills. This seems to be particularly important in developing regions of the world, where trust in firms and institutions (particularly in the legal and financial realm) is quite low (Delhey and Norton 2005). Amelia, a practitioner based in Cayman who deals primarily with clients from Africa and the Middle East, said that in her experience, 'You can't be this faceless professional. The client can't relate to just a suit and a briefcase ... You're creating a relationship, the same way you do friendships'.

This emphasis on highly individualized relations applies not just to wealth managers' encounters with clients. Rather, the whole business model depends on such personal linkages. Again, this is not unique to wealth management: as Hanlon observed more than a decade ago, 'Firms now constantly encourage individuals to build relationships with other professionals and clients in an attempt to place themselves in a social space where people think of them when potential business arrives' (2004: 203).

Although the significance of this individual agency has been de-emphasized in recent work on institutional change (Adamson, Manson, and Zakaria 2015), the data from wealth managers make clear that professionals - rather than their firms - are the crucial causal agents when it comes to expanding the practice of creating and managing trust structures. As Werner-a titled German noble who for 30 years headed the trust department at a private bank-explained, the spread of practices and ideas depends on individual wealth managers, rather than their firms: 'in our business ... you create personally a reputation, you create the organization's reputation'. This can occur through the everyday mechanism of individual career mobility. Werner elaborated:

'First of all, things get outside the bank-people leave, they get fired, and they carry stories to other areas within the profession ... the clients went to business school together or they have known each other for decades, and they talk to each other... and say "who's a good asset manager?"'

These peer-to-peer relationships constitute a vital mechanism in the spread of wealth management 


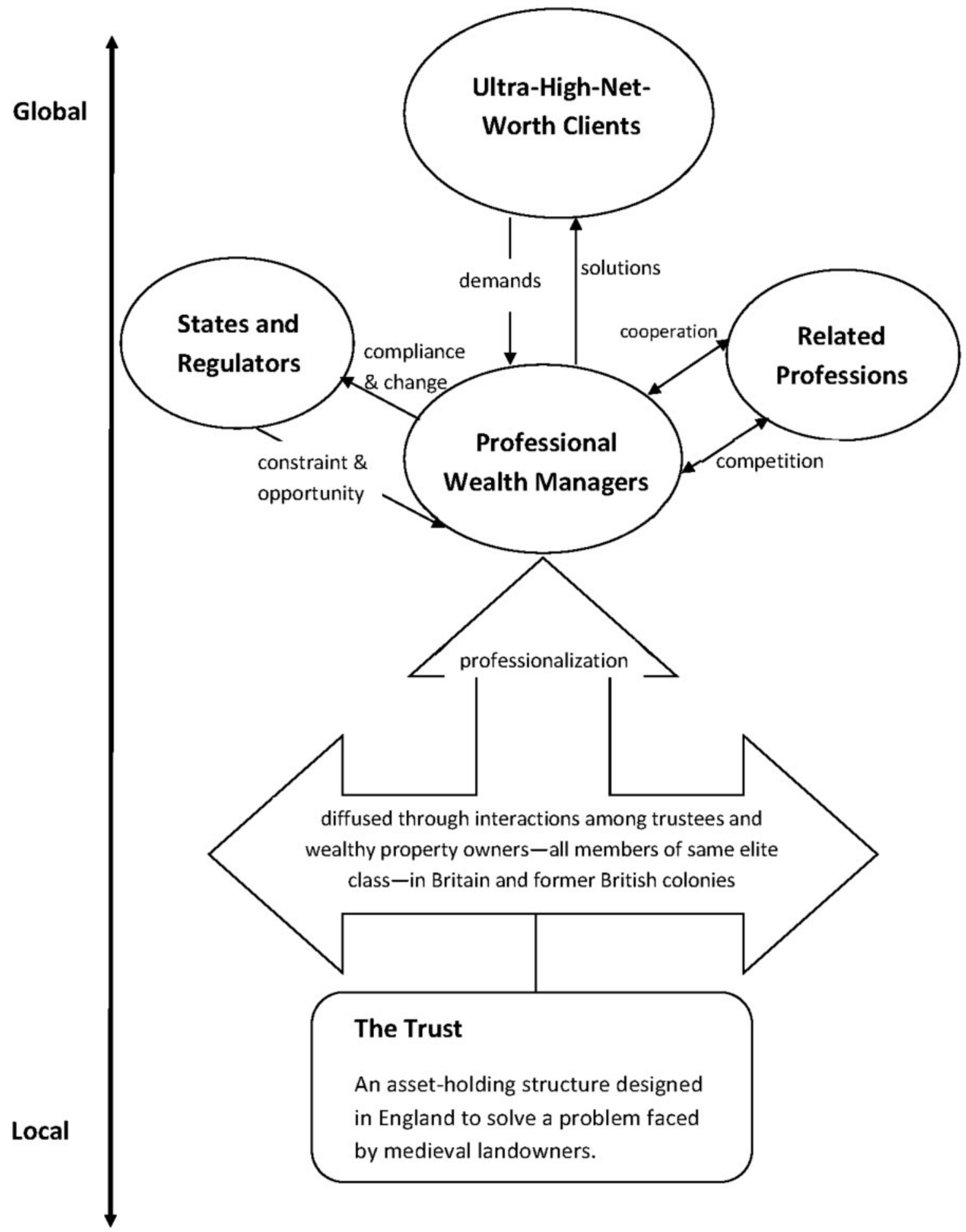

Figure 2. The trans-national institutionalization of the trust. 
All three forms of institutional work in wealth management have resulted in two key changes:

1) Trans-national adoption and recognition of trusts-isomorphism of international institutions with the trust

2) Modification of the traditional trust structure to meet contemporary local needs-isomorphism of the trust with indigenous institutions

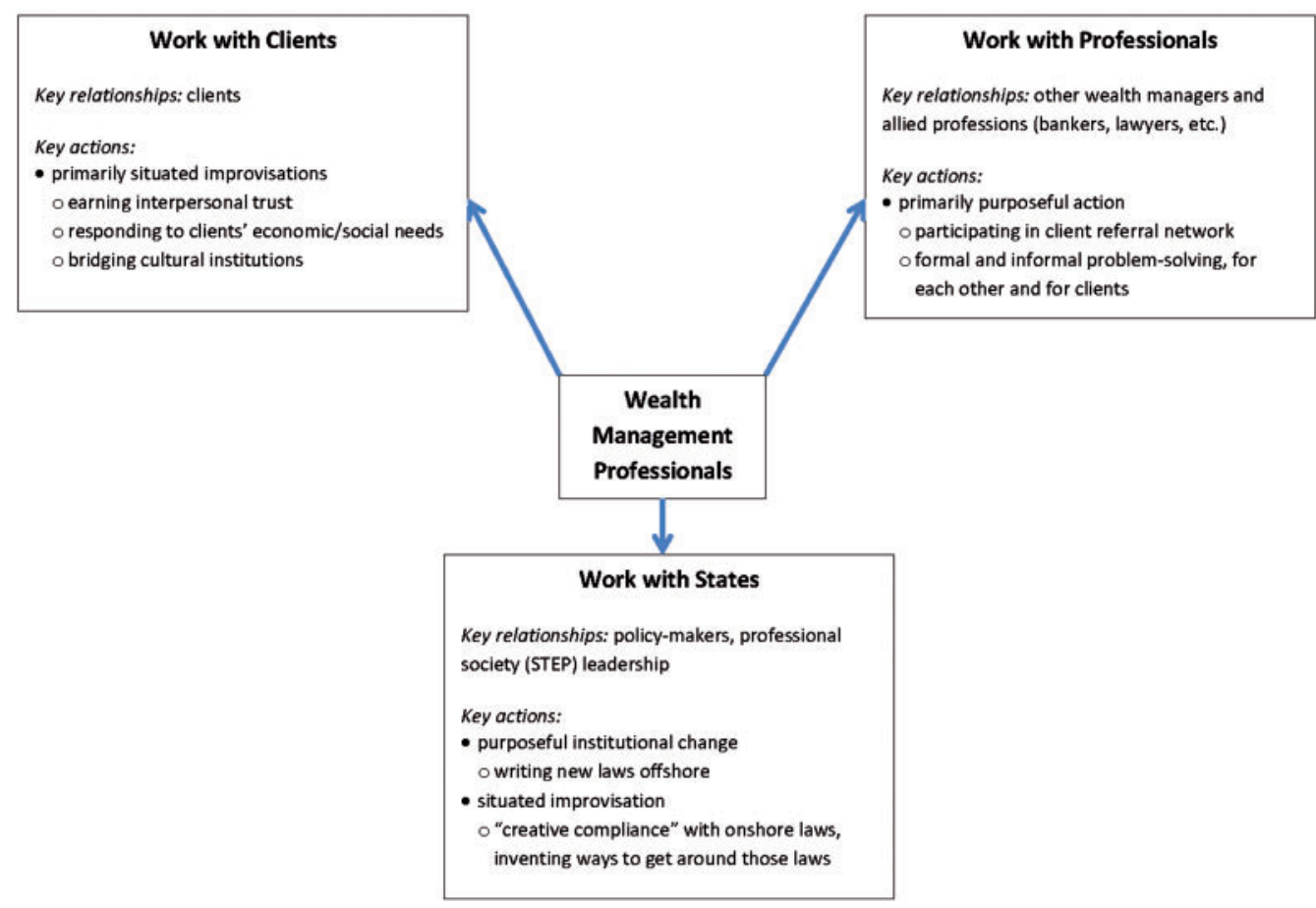

Figure 3. Key forms of relationality and institutional work in wealth management. All three forms of institutional work in wealth management have resulted in two key changes: (i) trans-national adoption and recognition of trustsisomorphism of international institutions with the trust; (ii) modification of the traditional trust structure to meet contemporary local needs-isomorphism of the trust with indigenous institutions.

practice, particularly with regard to trust structures. Although accepting new clients by referral only is the norm in financial services to elites (Winters 2011: $219)$, it is particularly common in wealth management, because trusts are so lightly regulated and so easily misused for money laundering and other activities that would pose a significant liability to professional fiduciaries (de Willebois et al. 2011). Faruq, the principal of a wealth management partnership in Mauritius explains that his practice grows as a direct result of his professional contacts: 'We don't accept walk-in clients. All our clients are referred by introducers, who are essentially other professionals, like tax planners and accountants. Those are relationships we trust'.
Surprisingly few studies treat inter-professional relationships as a catalyst for the diffusion of practices. Instead, the focus is more usually on intra-professional ties-for example, in Rao, Monin, and Durand's (2005) study of the competition among elite chefs that led to the diffusion of haute cuisine in France. However in the case of wealth managers, engagement not only with peers but with other, related professions has been instrumental in driving the diffusion of the trust structure.

Many of these opportunities to engage with other professionals stem from the multi-jurisdictional career paths common to wealth managers, which mirrors the trans-nationality of their client base. As Barnaby, a British trustee based in the Cayman 
Islands, pointed out, 'the typical career path of the wealth manager involves time both onshore and offshore, usually in several locations for several years'. Barnaby himself spent 6 years in London, and the past 2 years in Cayman, with the expectation that he would be transferred shortly to Singapore. This trans-national mobility, a defining characteristic of the wealth management profession, drives the diffusion of new ideas and practices (Davies 2012) and is crucial to the relational part of institutional work, expanding networks of trusting relations with clients and other professionals.

\section{Relationality and the local-global encounter}

One of the reasons wealth management offers such an interesting window into the dynamics of institutional change is the profession's positon on the front lines of encounters between the local and global levels. These individuals are personally responsible for spreading a practice of 'uniquely Anglo-American origin' (Langbein 1995: 69) trans-nationally. Their work with trusts exemplifies what McCann and Ward (2010: 176) called the intensely and fundamentally local, grounded and territorial' character of much professional activity, and underscores the need to understand how such practices 'go global'.

According to Alistair, a London-based fiduciary in his late 60s with a hereditary noble title and his own wealth management firm, trusts still occupy a distinctive role in the culture of the UK:

'As Brits, we're all hardwired for trusteeship. Everything is in trust here. Little tiny trusts from people's wills to keep the organ going at the village church ... there are thousands of these. The whole of English life is permeated, effectively with assuring continuity, of protecting the bell tower of their Norman church. We're hard-wired to think of that and how they operate, and making decisions as trustees.'

Prior to the emergence of wealth management as a formal profession, trust law diffused passively to all corners of the expanding British Empire as part and parcel of the common law tradition. In the 20th century; however, professional wealth managers actively expanded use of the trust in service to trans-national clients (Harrington 2012a, 2012b). As a result, trusts have gained de facto recognition even in countries that were never British colonies-as in Continental Europe, where the Civil Law tradition formally does not recognize the division of legal and beneficial ownership (Amos 1937; Hofri 2014).

Figure 2 traces these developments, from the origin of the trust as a highly localized phenomenon of 14th century England to a fixture of contemporary international finance. The figure then extends this path to illustrate the relational contexts in which wealth managers do their key institutional work. This shows in concrete, practice-oriented terms what it means to claim that globalization is a dynamic process continually re-enacted in interpersonal interactions.

As the figure suggests, a key institutional force in the diffusion of the trust beyond the realm of Britain and its former colonies has been the emergence of a global elite and their need for 'hypermobile' capital. The clientele served by wealth managers exists 'perpetually between nation-states, to the extent that they dwell in global space-time, not the space of the nation-state' (Beaverstock, Hubbard, and Short 2004: 405). Logistically and legally, this 'multi-territoriality' of elites and their wealth is only possible through the interventions of professionals and the strategic deployment of trusts. As Mark, a British lawyer now based in Dubai, explained:

'.. in the late 1990s, a new breed of superrich, the Forbes billionaire class exploded in numbers and haven't stopped growing. Who would have guessed in the 1980s that you could have an industry charging individuals for trust and estate services? And the reason is, those individuals have the wealth equivalent to small countries. The 21 st-century gazillionaire had, until recently, no wealth plan except maybe some boxes of documents in their office and personal assistant ... there is no skeleton there-no support structure to put the wealth into a meaningful, coherent plan. So my job is to put a skeleton in there, so the wealth doesn't turn to jelly when they die.'

As a practical matter, the client base for wealth management services is growing most rapidly in 
countries without a Common Law tradition or even formal recognition of trust structures; this includes countries such as China, Russia, Brazil, and the nations of the Arabian Peninsula (Marr 2014). The demand for trusts by clients from these countries stems in part from what Barnaby, the Cayman-based fiduciary, called 'the tight relationships among high-networth-individuals' - the diffusion of ideas and practices through closed networks of elites (e.g. Pincon and Pincon-Charlot 1998). Max, an American fiduciary based in Switzerland, mentioned that his Russian and Latin American clients 'just want the same structures as their friends have, regardless of whether their friends' solution really fits ... We'll explain why that's not a good idea, and they often say, "I don't care, I want what my friend has." Having the same thing as their friends makes them feel safe.' In this sense, relationality among high-networth clients has served the diffusion of the trust structure trans-nationally.

\section{Relationality as a catalyst for professional invention} The transnational mobility of elites and their capital has also led clients to present professional advisors with problems that seem best addressed through a trust structure. However, with clients who come from cultural and legal traditions where trusts are unknown, concepts such as divided ownership can present special challenges. The problem is particularly acute with 'new money' clients who may lack the networks that lead those with more established wealth to hear about trusts through their friends and relatives.

In these cases, diffusion of the trust in concept and practice depends crucially on the relational skills of professionals themselves. As Elias, a Panamanian wealth manager, explained: 'One of the main characteristics of Latin American clients, which are 98 percent of the people I work with, they feel that trusts don't give them enough control ... They don't trust trusts!' Solving this problem, he says, comes down to getting the client to trust you personally. Contrary to the implications of previous research (e.g. Fourcade 2006; Daudigeos 2013), Elias is at pains to point out that organizations and their reputations are less significant than individual rapport in the process of spreading professional practices. Diffusing acceptance of an 'alien' structure like the Anglo-American trust trans-nationally means 'Being able to make a connection with a client and making a person feel comfortable with you ... It's not just a matter of [the client] having confidence in the company providing services: the individual relationship is key.'

Often, encounters with clients from non-trust jurisdictions demand an inventive use of professionals' expertise, not just in financial and legal techniques, but in cultural terms (Perkmann and Spicer 2007). For Max, who is fluent in Arabic and has worked with Saudi clients for over a dozen years, the relational task involves articulating clients' local culture with the practices and norms of contemporary global finance:

'Trusts are a hard sell to Russian and Arab clients-like Paul was saying yesterday about working with the Chinese. They want to own things, especially Russians, so they can't understand why they should agree to give up that ownership and keep control. I try to tell them that it's much better to have control than ownership, but it's hard for them to understandculturally, it's an alien concept. They say, "why should I trust you?" That's a tough one, so I have to explain in terms of concepts that are already in their culture, like "amana"-this basic idea of trust, so that you can go off with the caravan to Syria, for example, and say to someone trustworthy, "I'm leaving for a few months, please take care of my stuff, and if I don't come back, please make sure my stuff goes to my son/wife/etc." The Prophet Muhammed was one of those people that other people found really trustworthy, and he was often asked to take care of their stuff for them, knowing he'd take better care of it than his own stuff.'

In order to adapt the institution of the trust to a new environment, to help it make the leap from the Anglo-Saxon to the Arab world, Bruce must engage in a special type of institutional work (Lawrence 1999; Fligstein 2001): putting new wine in old bottles, explaining the alien in terms of the familiar. This type of work may be particularly common in trans-national settings; it is especially important in the early stages of institutional change (Lawrence and Suddaby 2006). 
This work of articulating the old with the new also exemplifies how change is instigated in weaklyinstitutionalized 'gold rush' environments: 'by introducing old rule structures into new contexts, [institutional] entrepreneurs are able to legitimate certain actions and technologies, establish governance mechanisms, and institute themselves as professional authorities' (Lefsrud and Suddaby 2012: 335). In this case, the old rule structure is the trust, and the process of introducing it successfully requires the personal intervention of a professional equipped not just with technical skills, but with the deep socio-cultural knowledge that comes from embedded relationships.

Also noteworthy is the fact that Max solves the problem of client skepticism-'why should I trust you?' - without reference to his firm or the broader reputational appeal of Swiss banking. Instead, he draws on the history of Islam, which permeates both the environment and the worldview of his clients. Specifically, by referencing the concept of amana (in Arabic, أمانة) - which not only means 'trustworthiness', but is the second key attribute of the Prophet Muhammed-Max is asking clients to generalize from one personalized relationship (that of Muhammed with other traders) to another (that of the professional wealth manager with a client).

The data from this study suggest that this skill in embodying or enacting a cultural linkage in interpersonal settings has played a pivotal role in wealth management professionals' ability to diffuse the Anglo-American trust internationally. Didier, a French wealth manager who-like Max-works as a fiduciary for a primarily Saudi Arabian client base, described a similar strategy. Like Max, Didier makes no effort to assuage clients' concerns about trusts by referencing his firm's reputation or the protections offered by offshore jurisdictions where trusts can be located. Instead, Didier says, 'trust in this setting is all about face-to-face relationships'. Thus, he must be the personal ambassador for embodiment of and this professional practice.

To help his clients attain some level of comfort with the 'alien' concept of the trust, Didier points out to them its similarity to the traditional Islamic vakif, an ancient form of charitable foundation created by wealthy individuals, which has several important features in common with trusts, including: the function of passing wealth from one generation of a family to the next, and the separation of ownership from control via the management of assets by a third party (called a mutawillis), whose role is similar to that of a fiduciary (Zubaida 2006). That such articulation efforts are necessary speaks to the persistence and power of the local, even among members of the global elite.

\section{Relations with firms and states}

Organizations in the professional environment can provoke further invention in institutional work. Sometimes this occurs through the imposition of constraints on professional activity; in other cases, it is facilitated by the creation of new opportunities. For wealth managers, this distinction often takes shape around the divide between 'onshore' and 'offshore'. In this context, 'offshore' does not necessarily represent a geographical location at sea, but a special kind of jurisdiction-colloquially known as a 'tax haven'-whose laws are specifically designed to attract the custom of wealth managers and their clients.

The opportunities and constraints presented in these two environments give rise to distinct forms of institutional work. For example, the policy of 'blacklisting' offshore jurisdictions for failing to cooperate with onshore tax authorities did not have the intended effect-shrinking tax haven activity (Sharman 2006; Shaxson 2011) —but it did catalyse financial and legal innovation by professionals. To illustrate, Matt and Jamie, two young wealth managers from Johannesburg, explained how regulatory constraints have actually spurred practitioners to greater feats of 'creative compliance' (McBarnet 2005):

Matt: 'The trends [in the industry] are going to require us to be more creative as regulations become stricter and companies are required to be more transparent. The closing of tax loopholes is good business for us ...'

Jamie: 'Yeah, if you go anywhere in the world, some of the top tax practitioners in the world-US, London, Australia-are South African. Because we have such a complex system, we produce some of the most creative wealth management advisers in the world.' 
In practice, they explained, these workarounds and acts of 'creative compliance' are managed relationally: that is, through personal ties with other professionals, either in firms or government. Paul, an Englishman working in Dubai, elaborated on this strategy: 'We form relationships with people at banks and so forth in order to get things done that aren't necessarily formal.'

In offshore jurisdictions, these relationships with wealth management professionals are often actively solicited by governments and financial firms. For example, numerous offshore states have hired wealth managers to consult on and draft financial legislation, as part of the states' effort to gain advantage in the 'bitterly competitive market' (Economist 2013) among jurisdictions providing trust services. In some cases, states work directly with STEP - the professional association-to draft new laws. The bestknown case of this occurred in the British Virgin Islands, where a new trust law designed to attract wealth from Asia. However, even in that case, the effort was spearheaded by a particularly wellconnected and socially embedded professional in the BVI: as an article on the new law notes, it 'was drafted by a STEP committee headed by Chris McKenzie, the founding chairman of STEP's BVI branch' (Gray 2005).

Based on the interviews conducted for this study, it seems that formal involvement of STEP in drafting new laws is fairly uncommon. Rather, such collaborations more often take place through what Alan-the British fiduciary based in Hong Kong-called the 'informal relationship between regulators and professionals'. As a recent example, he noted, 'the Monetary Authority of Singapore just sent me their draft trust law for comments before it was released to the public'.

Examining these highly individual relationships between practitioners and states can provide insight on variations in the political economy of institutional change. For example, Lester-a British fiduciary whose 40-year career has ranged from a stint with the Rothschild family office to his current position at the helm of his own firm in Hong Kong-has been involved in writing the financial laws of several offshore jurisdictions in the Asia-Pacific region. As he observed,

'One of the places where the two worlds - that of the private wealth manager and that of the regulator or revenue authority-touch is in drafting the laws. The laws are written by specialized parliamentary counsel, so they have to reach out-usually through a ministry like financial services and treasury-to practitioners to understand the impact of the laws they're writing. It varies from jurisdiction to jurisdiction. In Hong Kong, the law is very profession-driven: the professions tell the government what laws need to be made. In Singapore, it's a lot more dictatorial and they tell the professions what to do. In Malaysia, they're quite different: they said, "we need this [trust law], but we don't know anything about it, so we're going to appoint a private law firm to consult with practitioners and draft the law, and we'll supervise it."'

These relational encounters between professionals and states create opportunities for changeoriented institutional work in two ways. The first is direct, as described earlier, when a professional is given the opportunity to draft new legislation. The second is indirect, and occurs when other jurisdictions pick up the new models or laws invented by the professionals. For example, the alternative trust regimes drafted by STEP members in the Caribbean are now being picked up and made into law in distant parts of the globe: Labuan, an island chain off the coast of Malaysia, recently passed its own Special Trusts Act, which has been marketed as 'Asia's answer to VISTA' (Grasby 2010; Lea 2010). This illustrates how professionals' institutional work can catalyse institutional change from afar, through isomorphism.

\section{DISCUSSION}

This study examines specific forms of agency and situated practice involved in the trans-national institutionalization of the Anglo-Saxon trust. This work is intended to shed light on nuances of agency that have been neglected by theories of institutional change. The article seeks to move the scholarly conversation away from a focus on 'professional projects' driven by deliberate planning and established routines (Larson 1977; Lawrence and Suddaby 2006; Suddaby and Viale 2011), to include improvisation 
and invention as legitimate and important forms of work (Boreham 1983; Smets and Jarzabkowski 2013). To achieve these goals, the article brings in the insights of relational theory.

Relational theory helps us address the gaps in knowledge that institutional research has left around individual agency and the mechanisms underlying change. A relational model, with its focus on the 'sociology of occasions' (Emirbayer 1997), directs our analytical attention to the unpredictable and unplanned in professionals' encounters with clients, peers, and organizations in their environments. Such experiences of novelty are central to the work of professionals in trans-national settings (Delmestri 2006), but overlooked in many institutional analyses. At the same time, theories of globalization have often assumed individual agency without offering a systematic analysis of the mechanisms. These theoretical omissions can be addressed in part through the linkage of relationality and institutionalism proposed here.

The data presented in this article offer a concrete, agency-centered perspective on the relational work through which professionals effect institutional change. Although Fig. 2 charts the historical trajectory of the trust as a 'globalized localism' (Santos 2002), Fig. 3 details the micro-level encounters which have contributed to the institutionalization of trusts. It identifies specific types of work-both planned and improvisational - in which wealth managers engage with three key constituencies: clients, other professionals, and policy makers.

For example, while the trans-national institutionalization of the trust has taken place formally through international legal accords such as The Hague Convention on the Law Applicable to Trusts and Their Recognition (Hayton 1987), actually getting high-net-worth individuals to accept and adopt trusts in the management of their own fortunes is an entirely different matter. As Elias said of his South American clientele, 'They don't trust trusts!' Even with the authority and reputation of their firms behind them, individual professionals in this study were only able to put trusts into practical, everyday use through situated improvisations. First, they had to establish personal trust-an idiosyncratic task that several compared with building a friendship - and then they had to invent bridges between cultures and institutions, as Max and Didier did by showing their clients from the Arab Peninsula how trusts were compatible with Islamic tradition.

Similarly, significant institutional work with other professionals often took on an informal, improvisational character, motivated by the need to solve specific, situated problems. This includes what Paul in Dubai called the everyday necessity for wealth managers to work with bankers and other allied professions 'to get things done that aren't necessarily formal'. Such professional ties were also essential to the creation and maintenance of the international client referral network, on which the profession depends to protect itself from liabilities such as involvement in money laundering, tax evasion, and other illegal activities.

Such informal institutional work occurs in parallel to the formal efforts at institutional change being carried out by STEP, which builds intra- and inter-professional alliances as part of its strategy to advance the profession. STEP also lobbies legislatures and forms educational partnerships with universities to promote the diffusion of trusts (Harrington 2012a). Individual professionals participate in some of this formal institutional change activity, such as when they accept work in writing the financial laws of offshore financial centers. But then many of them simultaneously engage in 'creative compliance' (McBarnet 2005) - a form of legal improvisation directed at solving the situated problems of individual clients. Some of these efforts, intended as one-off solutions, end up becoming international standards, or 'globalized localisms' (Santos 2002).

Each of the three kinds of everyday institutional work by wealth managers has facilitated isomorphic adaptation (Jepperson 1991), either of international institutions to the trust, or of the trust to local norms. This dual action-globalizing a localism, and localizing a globalism-is an essential characteristic of trans-nationalized institutions. What is new in this article is the ability to specific the precise forms of work and interpersonal encounters leading to this result. Figure 3 thus provides a concrete illustration of Boreham's (1983: 698) observation that the application of knowledge to practical affairs by individual practitioners is filtered through a number of important social processes.' 


\section{CONCLUSION AND IMPLICATIONS FOR} FUTURE RESEARCH

Overall, the findings of this study suggest that the theoretical significance of wealth management professionals in globalization arises from the special mix of planned and improvisational agency they employ. This is not the 'critical project' (Fiss and Hirsch 2005) or 'world society' (Meyer et al. 1997) version of institutional work, which foregrounds collective action and intentional strategies. Instead, the model presented here offers a more nuanced and situated account of agency, acknowledging that institutional change sometimes arises from invention and the application of expert knowledge to the unexpected.

With respect to previous work, this article answers calls to develop the micro-macro link (Suddaby and Viale 2011; Powell and Colyvas 2008). It offers a multi-level account of the interplay between trans-national institutions and the micro-level practices of individual professionals. Furthermore, it extends recent research on invention and institutional change by specifying a model of the 'quiet, unobtrusive process of diffusion that avoids regulatory pushback, increasing the likelihood of practice improvisations leading to institutional change' (Smets, Morris, and Greenwood 2012: 878). In particular, it offers a view of micro-level institutional work that is neither accidental nor the result of strategic planning, but rather driven by incremental problem solving catalyzed by the challenges of institutions intersecting across national boundaries. This points up a potential limitation of this study: situated improvisations may occur more readily in the kind of environment faced by wealth management professionals, in which structures and routines are still emergent, and the 'concrete' of institutions remains malleable in the hands of individual practitioners.

Future research can build on this study in three ways. First, it can continue to challenge the narrow construction of agency in institutional change with work focused on relationality and interaction-a once-vibrant stream of research that has been neglected in recent years (Harrington and Fine 2006, 2000). Second, it can advance the literature on the institutional work with cases involving more stable and established structural environments. Third, future research can contribute to the literature on the professions by extending the model presented here to look at other expressions of agency in trans-national settings. Unlike previous studies which focused on established and well-defined professions, such as law, accounting, or finance (e.g. Dezelay and Garth 1995; Frankel 1998; Greenwood, Suddaby, and Hinings 2002), this examination of wealth management involves a broad ensemble of actors, whose boundaries of practice are undergoing rapid revision. As 'fast subjects' operating in trans-national space (Baumann 2000), these individuals may well represent the future of professional work in a globalized world.

\section{FUNDING}

This study was supported by the Max Planck Institute for the Study of Societies, as well as by grants from the American Sociological Association (Fund for the Advancement of the Discipline), the Alexander von Humboldt Foundation (1127465), and the European Research Council (263741PIPES).

\section{ENDNOTES}

1. To illustrate the international scope of contemporary trust activity, consider the following 'typical client' scenario presented in a training manual for professional wealth managers:

'the proposed settlor [the person putting assets into trust] is a Brazilian national, but has been living in Canada for the last 15 years where he considers his permanent home to be. The trustees are to be a trust institution in the Cayman Islands with a professional protector situated in the Bahamas. It is intended that the trust assets will comprise shares in two underlying companies: the holding company of the settlor's Latin American business empire is incorporated as an exempt company in Bermuda; and an IBC incorporated in BVI holding a portfolio of stocks and shares. The discretionary beneficiaries [the people entitled to use of the trust assets, at the trustees' discretion] comprise a class of persons who reside throughout Europe and South America' (Parkinson 2005: 220).

This example, in which trust activity is spread over three continents and more than half a dozen countries, suggests why wealth management professionals need to coordinate with a team of international experts.

2 This study acknowledges that is it problematic to classify people by race and ethnicity. For example, the category 'Black' in this context includes people who identify as African-American, Afro- 
Caribbean, Seychellois, Mauritian, and as bi- or multi-racial. In this sense, racial-ethnic groupings are bound to be inaccurate and reductive. However, within the context of the broader demographic picture presented here, information about race and ethnicity may be helpful-particularly since a majority of interview participants mentioned that culture and identification play a significant role in the establishment of trust between professionals and their clients. The importance of perceived racial and ethnic similarity between professionals and clients has also been documented in recent research (Hsu, Hackett, and Hinkson 2014).

\section{REFERENCES}

Abbott, A. (1991) 'The Order of the Professions: An Empirical Analysis', Work and Occupations, 18: 355-84.

- (1988) The System of the Professions: An Essay on the Division of Expert Labor. Chicago: University of Chicago Press.

Adamson, M., Manson, S., and Zakaria, I. (2015) 'Executive Remuneration Consultancy in the UK: Exploring a Professional Project Through the Lens of Institutional Work', Journal of Professions and Organizations, 2: 19-37.

Amos, S. (1937) 'The Common Law and the Civil Law in the British Commonwealth of Nations', Harvard Law Review, 50: 1249-74.

Baker, T. and Nelson, R. (2005) 'Creating Something from Nothing: Resource Construction through Entrepreneurial Bricolage', Administrative Science Quarterly, 50: 329-366.

Bauman, Z. (2000) Liquid Modernity. New York: Wiley.

Beaverstock, J., Hubbard, P., and Short, J. (2004) 'Getting Away with It? Exposing the Geographies of the Superrich', Geoforum, 35: 401-7.

Brint, S. and Karabel, J. (1989) The Diverted Dream: Community Colleges and the Promise of Educational Opportunity in America, 1900-1985. New York: Oxford.

Boreham, P. (1983) 'Indetermination: Professional Knowledge, Organization and Control', Sociological Review, 31: 693-718.

Carruthers, B. and Halliday, T. (2006) 'Negotiating Globalization: Global Scripts and Intermediation in the Construction of Asian Insolvency Regimes', Law and Social Inquiry, 31: 521-84.

Cox, V. (2013) 'Skills That Make a Difference', STEP Journal, July. <http://www.step.org/skills-make-difference> accessed 14 Jan 2015.

de Willebois, E., Halter, E. Harrison, R. et al. (2011). The Puppet Masters: How the Corrupt Use Legal Structures to Hide Stolen Assets and What to Do About It. Washington, DC: World Bank.

Daudigeos, T. (2013) 'In Their Profession's Service: How Staff Professionals Exert Influence in Their Organization', Journal of Management Studies, 50: 722-49.

Davies, W. (2012) 'Climate, Creativity, and Competition: Evaluating the Neanderthal "Glass Ceiling”". In: S., Elias (ed.) Origins of Human Innovation and Creativity, pp. 108-28. Oxford: Elsevier.
Delhey, J. and Newton, K. (2005) 'Predicting Cross-national Levels of Social Trust: Global Pattern or Nordic Exceptionalism?' European Sociological Review, 21: 311-27.

Delmestri, G. (2006) 'Streams of Inconsistent Institutional Influences: Middle Managers as Carriers of Multiple Identities', Human Relations, 59: 1515-41.

Dezalay, Y. (1990) 'The Big Bang and the Law'. In: M., Featherstone (ed.) Global Culture: Nationalism, Globalization and Modernity, pp. 279-94. London: Sage.

—. and Garth, B. (1995) 'Merchants of Law as Moral Entrepreneurs: Constructing International Justice from the Competition for Transnational Business Disputes', Law and Society Review, 29: 27-64.

_ \& - (2002) The Internationalization of Palace Wars: Lawyers, Economists, and the Contest to Transform Latin American States. Chicago: University of Chicago Press.

Dicken, P., Kelly, P., Olds, K., and Yeung, H. (2001) 'Chains and Networks, Territories and Scales: Towards a Relational Framework for Analyzing the Global Economy', Global Networks, 1: 89-112.

Economist. (2013) 'Trawling for Business: The Gambia Looks to Join A Beleaguered Club', Economist, August 24. $<$ http://www.economist.com/news/finance-and-economics/21584019-gambia-looks-join-beleaguered-club-trawling-business $>$ accessed 10 Dec 2014.

Eisenhardt, K. (1989) 'Building Theories from Case Study Research', Academy of Management Review, 14: 532-50.

Emirbayer, M. (1997) 'Manifesto for a Relational Sociology', American Journal of Sociology, 103: 281-317.

Faulconbridge, J. (2007) 'Relational Networks of Knowledge Production in Transnational Law Firms', Geoforum, 38: 925-40.

(2008) 'Managing the Transnational Law Firm: A Relational Analysis of Professional Systems, Embedded Actors and Time-Space-Sensitive Governance', Economic Geography, 84: 185-210.

Fiss, P. and Hirsch, P. (2005) 'The Discourse of Globalization: Framing and Sensemaking of an Emerging Concept', American Sociological Review, 70: 29-52.

Fligstein, N. (2001) 'Social Skill and the Theory of Fields', Sociological Theory, 19: 105-25.

Fourcade, M. (2006) 'The Construction of a Global Profession: The Transnationalization of Economics', American Journal of Sociology, 112: 145-94.

_. and Savelsberg, J. (2006) 'Introduction: Global Processes, National Institutions, Local Bricolage: Shaping Law in an Era of Globalization', Law and Social Inquiry, 31: 513-9.

Frankel, T. (1998) 'Cross-Border Securitization: Without Law, But Not Lawless' Duke Journal of Comparative and International Law, 8: 255-82. 
Freidson, E. (2001) Professionalism: The Third Logic. Chicago: University of Chicago Press.

Grasby, R. (2010) 'Are Any Two Structures the Same?', STEP Journal, January. <http://www.step.org/are-any-twostructures-same $>$ accessed 12 Jun 2013.

Gray, S. (2005) 'VISTA Trusts Allow BVI to Slough Off Past and Attract Global Businesses', The Lawyer, 17 January. <http://www.thelawyer.com/vista-trusts-allowbvi-to-slough-off-past-and-attract-global-businesses/113609.article $>$ accessed 12 June 2013.

Greenwood, R., Suddaby, R., and Hinings, C. R. (2002). 'Theorizing Change: The Role of Professional Associations in the Transformation of Institutionalized Fields', Academy of Management Journal, 45: 58-80.

Hanlon, G. (2004) 'Institutional Forms and Organizational Structures: Homology, Trust and Reputational Capital in Professional Service Firms', Organization, 11: $186-210$.

Harrington, B. (2012a) 'Trust and Estate Planning: The Emergence of a Profession and Its Contribution to SocioEconomic Inequality', Sociological Forum, 27: 825-846.

- (2012b) 'From Trustees to Wealth Managers'. In: G., Erreygers and J., Cunliffe (eds.) Inherited Wealth, Justice, and Equality, pp. 190-209. London: Routledge.

—. and Fine, G. (2006) 'Where the Action Is: Small Groups and Contemporary Sociological Theory', Small Group Research, 37: 1-16.

— \& _ (2000) 'Opening the 'Black Box:' Small Groups and 21st Century Sociology', Social Psychology Quarterly, 63: 312-323.

Hayton, D. (1987) 'The Hague Convention on the Law Applicable to Trusts and on Their Recognition', International and Comparative Law Quarterly, 36: 260-82.

Hofri, A. (2014) 'Professionals' Contribution to the Legislative Process: Between Self, Client, and the Public', Law and Social Inquiry, 39: 96-126.

Holm, P. (1995) 'The Dynamics of Institutionalization: Transformation Processes in Norwegian Fisheries', Administrative Science Quarterly, 40: 398-420.

Howcroft, B., Hewer, P., and Hamilton, R. (2003) 'Consumer Decision-Making Styles and the Purchase of Financial Services', The Service Industries Journal, 23: 63-81.

Hsu, B., Hackett, C., and Hinkson, L. (2014) 'The Importance of Race and Religion in Social Service Providers', Social Science Quarterly, 95: 393-410.

Hughes, J. (1997) Family Wealth: Keeping It in the Family. Princeton Junction, NJ: NetWrx Inc.

Jenson, J. and de Sousa Santos, B. (2000) 'Introduction: Case Studies and Common Trends in Globalizations'. In: J., Jenson and B. De Sousa Santos (eds.) Globalizing Institutions: Case Studies in Regulation and Innovation, pp. 9-26. Aldershot, UK: Ashgate.

Jepperson, R. (1991) 'Institutions, Institutional Effects and Institutionalism’. In: W., Powell and P., DiMaggio (eds.)
The New Institutionalism in Organizational Analysis, pp. 143-63. Chicago: University of Chicago Press.

Kim, H. (2009) 'Market Uncertainty and Socially Embedded Reputation', American Journal of Economics and Sociology, 68: 679-701.

Langbein, J. (1995) 'The Contractarian Basis of the Law of Trusts', Yale Law Journal, 105: 625-75.

- (1997) 'The Secret Life of the Trust: The Trust as an Instrument of Commerce', Yale Law Review, 107: 165-89.

Larson, M. (1977) The Rise of Professionalism: A Sociological Analysis. Berkeley: University of California Press.

Lawrence, T. (1999) 'Rituals and Resistance: Membership Dynamics in Professional Fields', Human Relations, 57: 115-43.

- and Suddaby, R. (2006) 'Institutions and Institutional Work'. In: S., Clegg, C., Hardy, T., Lawrence, and W., Nord (eds.) The Sage Handbook of Organization Studies, pp. 215-54, 2nd edn. London: Sage

Lea, M. (2010) 'Twenty-First Century Trusts', STEP Journal, February. <http://www.step.org/are-any-two-structuressame $>$ accessed 12 Jun 2013.

Lefsrud, L. and Suddaby, R. (2012) 'After the Gold Rush: The Role of Professionals in the Emergence and Configuration of Organizational Fields'. In: M., Reihlen and A., Werr (eds.) Handbook of Research on Entrepreneurship in Professional Services, pp. 318-39. Cheltenham, UK: Edward Elgar.

Loewenstein, J. (2014) 'Take My Word for It: How Professional Vocabularies Foster Organizing', Journal of Professions and Organizations, 1: 65-83.

McBarnet, D. (2005) 'After Enron: Corporate Governance, Creative Compliance and the Uses of Corporate Social Responsibility'. In J., O'Brien (ed.) Governing the Corporation: Regulation and Corporate Governance in an Age of Scandal and Global Markets, pp. 205-22. New York: John Wiley \& Sons.

McCann, E. and Ward, K. (2010) 'Relationality/Territoriality: Toward a Conceptualization of Cities in the World", Geoforum, 41: 175-84.

Malsch, B. and Gendron, Y. (2013) 'Re-Theorizing Change: Institutional Experimentation and the Struggle for Domination in the Field of Public Accounting, Journal of Management Studies, 50: 870-99.

Maitland, F. (2011 [1909]) Equity: A Course of Lectures. Cambridge: Cambridge University Press.

Marr, R. (2014) 'Jersey: Riding the Tides of Change', STEP Journal, 75.

Meyer, J., Boli, J., Thomas, G., and Ramirez, F. (1997) 'World Society and the Nation-State', American Journal of Sociology, 103: 144-81.

Muzio, D. and Kirkpatrick, L. (2011) 'Reconnecting the Study of Professional Organizations with the Study of Professional Occupations', Current Sociology, 59: 389-405. 
Muzio, D., , Brock, D., and Suddaby, R. (2013) 'Professions and Institutional Change: Towards an Institutionalist Sociology of the Professions', Journal of Management Studies, 50: 699-721.

Parkinson, M. (2005) Trust Creation: Law and Practice, 3rd edn. Birmingham, UK: Central Law Training.

- (2008) Trustee Investment and Financial Appraisal, 4th Edition. Birmingham, UK: Central Law Training.

Perkmann, M. and Spicer, A. (2007) 'Healing the Scars of History: Projects, Skills and Field Strategies in Institutional Entrepreneurship', Organization Studies, 28: 1101-22.

Pincon, M. and Pincon-Charlot, M. (1998) Grand Fortunes: Dynasties of Wealth in France. (Trans. Andrea Lyn Secara.) New York: Algora Publishing.

Poulantzas, N. (2000) State, Power, Socialism. London: Verso.

Powell, W. and Colyvas, J. (2008) 'Microfoundations of Institutional Theory'. In: R., Greenwood, C., Oliver, K., Sahlin-Andersson, and R., Suddaby (eds.) Handbook of Organizational Institutionalism, pp. 276-98. Thousand Oaks, CA: Sage.

Rao, H., Monin, P., Durand, R. (2005) 'Border Crossing: Bricolage and the Erosion of Culinary Categories in French Gastronomy', American Sociological Review, 70: $868-991$.

Santos, B. (2002) Toward a New Legal Common Sense: Law, Globalization and Emancipation. London: Butterworths.
Sharman, J. (2006) Havens in a Storm: The Struggle for Global Tax Regulation. Ithaca, NY: Cornell University Press.

Shaxson, N. (2011) Treasure Islands: Tax Havens and the Men Who Stole the World. London: Random House.

Sherman, R. (2011) “"Time Is Our Commodity:” Gender and the Struggle for Occupational Legitimacy Among Personal Concierges', Work and Occupations, 37: 81-114.

Skocpol, T. (1979) States and Social Revolutions: A Comparative Analysis of France, Russia, and China. Cambridge: Cambridge University Press.

Smets, M. and Jarzabkowski, P. (2013) 'Reconstructing Institutional Complexity in Practice: A Relational Model of Institutional Work and Complexity', Human Relations, 66: 1279-309.

—, Morris, T., and Greenwood, R. (2012) 'From Practice to Field: A Multilevel Model of Practice-Driven Institutional Change', Academy of Management Journal, 55: 877-904.

Suddaby, R. and Viale, T. (2011) 'Professionals and FieldLevel Change: Institutional Work and the Professional Project', Current Sociology, 59: 423-42.

Thornton, P., Ocasio, W., and Lounsbury, M. (2012) The Institutional Logics Perspective: A New Approach to Culture, Structure and Process. Oxford: Oxford University Press.

Winters, J. (2011) Oligarchy. New York: Cambridge.

Zubaida, S. (2006) 'Max Weber's The City and the Islamic City', Max Weber Studies, 6: 111-8. 